\title{
Snoring during Bronchoscopy with Moderate Sedation Is a Predictor of Obstructive Sleep Apnea
}

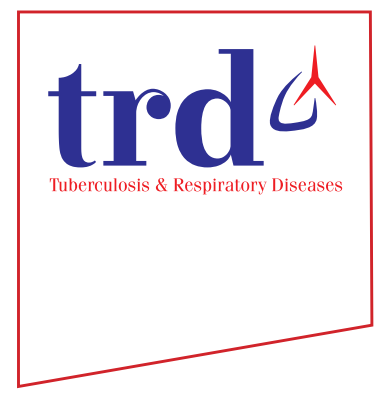

\author{
Jaeyoung Cho, M.D. ${ }^{1}{ }^{(i)}$, Sun Mi Choi, M.D. ${ }^{1}$, Young Sik Park, M.D. ${ }^{1}$, Chang-Hoon Lee, M.D., Ph.D. ${ }^{1}$, \\ Sang-Min Lee, M.D., Ph.D. ${ }^{1,2}$ and Jinwoo Lee, M.D. ${ }^{1,2}$ (i) \\ ${ }^{1}$ Division of Pulmonary and Critical Care Medicine, Department of Internal Medicine, Seoul National University Hospital, \\ Seoul, ${ }^{2}$ Department of Internal Medicine, Seoul National University College of Medicine, Seoul, Korea
}

Background: Snoring is the cardinal symptom of obstructive sleep apnea (OSA). Snoring and upper airway obstruction associated with major oxygen desaturation may occur in populations undergoing flexible bronchoscopy.

Methods: To evaluate the prevalence of patients at a high risk of having OSA among patients undergoing bronchoscopy with sedation and to investigate whether snoring during the procedure predicts patients who are at risk of OSA, we prospectively enrolled 517 consecutive patients who underwent the procedure with moderate sedation. Patients exhibiting audible snoring for any duration during the procedure were considered snorers. The STOP-Bang (Snoring, Tiredness, Observed apnea, high blood Pressure-Body mass index, Age, Neck circumference and Gender) questionnaire was used to identify patients at high (score $\geq 3$ out of 8 ) or low risk (score $<3$ ) of OSA.

Results: Of the 517 patients, 165 (31.9\%) snored during bronchoscopy under sedation. The prevalence of a STOP-Bang score $\geq 3$ was $61.9 \%(320 / 517)$, whereas 200 of the 352 nonsnorers $(56.8 \%)$ and 120 of the 165 snorers $(72.7 \%)$ had a STOP-Bang score $\geq 3$ ( $\mathrm{p}=0.001$ ). In multivariable analysis, snoring during bronchoscopy was significantly associated with a STOP-Bang score $\geq 3$ after adjustment for the presence of diabetes mellitus, chronic obstructive pulmonary disease, chronic kidney disease, and stroke (adjusted odds ratio, 1.91; 95\% confidence interval, 1.26-2.89; $\mathrm{p}=0.002$ ).

Conclusion: Two-thirds of patients undergoing bronchoscopy with moderate sedation were at risk of OSA based on the screening questionnaire. Snoring during bronchoscopy was highly predictive of patients at high risk of OSA.

Keywords: Snoring; Bronchoscopy; Conscious Sedation; Sleep Apnea, Obstructive

\section{Introduction}

Address for correspondence: Jinwoo Lee, M.D.

Department of Internal Medicine, Seoul National University College of

Medicine, 103 Daehak-ro, Jongno-gu, Seoul 03080, Korea

Phone: 82-2-2072-7593, Fax: 82-2-762-9662

E-mail: realrain7@gmail.com

Received: Jan. 28, 2019

Revised: Apr. 1, 2019

Accepted: Apr. 5, 2019

Published online: May. 31, 2019

(c) It is identical to the Creative Commons Attribution Non-Commercial License (http://creativecommons.org/licenses/by-nc/4.0/).

Copyright $\subset 2019$

The Korean Academy of Tuberculosis and Respiratory Diseases.
Obstructive sleep apnea (OSA) is recognized as the occurrence of repetitive episodes of partial airway collapse, manifested as loud snoring and hypopnea, or complete airway collapse, manifested as apnea, which results in oxygen desaturation or arousal during sleep. In the 1990s, the prevalence of OSA was $4 \%$ in middle-aged men and $2 \%$ in middle-aged women ${ }^{1}$. However, the prevalence of OSA has increased substantially over the past two decades, ranging from $10 \%$ to $20 \%$, with the increasing prevalence of obesity and advanced age $\mathrm{e}^{2,3}$. OSA is frequently comorbid with cardiovascular, cerebrovascular, and metabolic diseases ${ }^{4}$, and is responsible for poor quality of life and increased health care use costs ${ }^{5}$. Furthermore, OSA is associated with high morbidity and mortality rates ${ }^{6,7}$.

However, OSA remains underdiagnosed; up to $80 \%$ of pa- 
tients with moderate to severe OSA are estimated to remain undiagnosed in the general population ${ }^{8}$. Even in surgical patients, approximately $60 \%$ of those with moderate to severe OSA are not recognized preoperatively ${ }^{9,10}$. Thus, efforts have been made to devise simple screening instruments to identify patients who are undiagnosed but at high risk of OSA because overnight polysomnography is time-consuming, labor-intensive, and costly ${ }^{11-14}$.

Snoring is the cardinal symptom of OSA. Both male and female habitual snorers are more likely to have an apnea-hypopnea index (AHI) of 15 or higher ${ }^{1}$. By contrast, the absence of snoring makes OSA less likely.

Although flexible bronchoscopy is a generally safe and minimally invasive diagnostic procedure, patients with OSA may have an increased risk of obstructive episodes during procedures with moderate sedation ${ }^{15}$. Snoring and upper airway obstruction associated with oxygen desaturation have been reported to occur in patients undergoing bronchoscopy $^{16}$. However, the association between snoring during bronchoscopy and OSA remains largely unexplored. Here, we aimed to evaluate the prevalence of patients at a high risk of having OSA in a population undergoing bronchoscopy with moderate sedation and to investigate whether snoring during the procedure predicts patients who are at risk of OSA. Detecting additional clinical predictors of OSA may help identify patients for whom further evaluation of OSA is necessary.

\section{Materials and Methods}

\section{Study design and patients}

We prospectively enrolled consecutive patients who were 18 years or older and undergoing flexible bronchoscopy with moderate sedation in the bronchoscopy center at Seoul National University Hospital between 27 December 2016 and 1 October 2018. Patients were excluded from the study if they had a previous diagnosis of OSA, an American Society of Anesthesiologists physical status $>3$, or baseline pulse oximeter oxygen saturation $\left(\mathrm{SpO}_{2}\right)<90 \%$, or used a tracheostomy tube, needed supplemental oxygen before the procedure, or had been scheduled to undergo bronchoalveolar lavage, endobronchial ultrasound-guided transbronchial needle aspiration, or interventional bronchoscopy.

This study was approved by the Institutional Review Board of Seoul National University Hospital (H-1612-041-813). All participants provided written informed consent and the study was conducted in accordance with the tenets of the Declaration of Helsinki.

\section{Screening for OSA}

The STOP-Bang (Snoring, Tiredness, Observed apnea, high blood Pressure-Body mass index, Age, Neck circumference and Gender) questionnaire was adopted as a screening tool for OSA in the present study ${ }^{11}$. The STOP-Bang questionnaire was developed and validated to identify patients with undiagnosed OSA in preoperative clinics. The questionnaire comprises eight yes-or-no questions (snoring, tiredness, observed apnea, high blood pressure, body mass index [BMI] $>35 \mathrm{~kg} /$ $\mathrm{m}^{2}$, age $>50$ years, neck circumference $>40 \mathrm{~cm}$, and male sex). It has a high sensitivity at a cutoff score of $\geq 3: 84 \%$ in detecting any OSA (AHI $>5 / \mathrm{hr}$ ) and $93 \%$ in detecting moderate to severe OSA $(\mathrm{AHI}>30 / \mathrm{hr})^{11}$. A recent study proposed an alternative model for scoring the STOP-Bang questionnaire to improve the specificity for detecting moderate to severe OSA ${ }^{17,18}$. According to the alternative model, participants are classified into three groups based on the STOP-Bang score: low (0-2), intermediate (3-4), and high risk (5-8). Those with STOPBang scores of 3 or 4 can be further classified as having a high risk of moderate to severe OSA if they have both a STOP (snoring, tiredness, observed apnea, high blood pressure) score of $\geq 2$ and meet one of the following criteria: (1) BMI $>35$ $\mathrm{kg} / \mathrm{m}^{2}$, (2) neck circumference $>40 \mathrm{~cm}$, or (3) male sex ${ }^{17,18}$. The results of the questionnaire were not disclosed to the attending nurses and bronchoscopists.

\section{Sedation and monitoring}

Our routine practice for flexible bronchoscopy is to use moderate sedation with intravenous midazolam. Midazolam was administered by an experienced nurse and titrated by the attending bronchoscopist. If required, $50 \mu \mathrm{g}$ of fentanyl as an adjuvant was infused at the bronchoscopist's discretion. From the onset of sedation, all patients were provided with $3 \mathrm{~L} / \mathrm{min}$ of supplemental oxygen by nasal cannula with continuous pulse oximetry and electrocardiography, and intermittent blood pressure monitoring. Snoring during bronchoscopy was also monitored. Patients exhibiting audible snoring for any duration during the procedure were considered snorers in this study.

\section{Statistical analysis}

Clinical characteristics were compared between snorers and nonsnorers using the independent samples $t$ test for continuous variables. Categorical variables were compared using either the chi-square test or Fisher exact test. Multivariable logistic regression was performed to evaluate the association of snoring during bronchoscopy with a STOP-Bang score $\geq 3$ adjusted for variables with $\mathrm{p}$-values of $<0.05$ in univariable analysis considering collinearity.

A p-value of less than 0.05 was considered significant. Statistical analyses were performed using Stata statistical software (version 13.1, StataCorp LP, College Station, TX, USA). 


\section{Results}

Among the 544 patients who were enrolled during the study period, 27 were excluded from the analysis because of incomplete documentation. Of the 517 included patients, 165 (31.9\%) snored during bronchoscopy under moderate

Table 1. Characteristics of study patients

\begin{tabular}{|c|c|c|c|}
\hline & Nonsnorers $(\mathrm{n}=352)$ & Snorers $(\mathrm{n}=165)$ & p-value \\
\hline \multicolumn{4}{|l|}{ Patient characteristics } \\
\hline Age, yr & $63.0 \pm 11.7$ & $66.0 \pm 10.0$ & 0.003 \\
\hline Male sex & $181(51.4)$ & $126(76.4)$ & $<0.001$ \\
\hline $\mathrm{BMI}, \mathrm{kg} / \mathrm{m}^{2}$ & $22.6 \pm 3.1$ & $23.9 \pm 3.3$ & $<0.001$ \\
\hline Smoking & & & 0.002 \\
\hline Never-smoker & $187(53.1)$ & $60(36.4)$ & \\
\hline Former smoker & $107(30.4)$ & $70(42.4)$ & \\
\hline Current smoker & $58(16.5)$ & $35(21.2)$ & \\
\hline Inpatient & $302(85.8)$ & $141(85.5)$ & 0.918 \\
\hline ASA physical status & & & 0.289 \\
\hline I & $0(0)$ & $0(0)$ & \\
\hline II & $261(74.2)$ & $115(69.7)$ & \\
\hline III & $91(25.9)$ & $50(30.3)$ & \\
\hline \multicolumn{4}{|l|}{ Comorbidity } \\
\hline Hypertension & $137(38.9)$ & $74(44.9)$ & 0.201 \\
\hline Diabetes mellitus & $54(15.3)$ & $39(23.6)$ & 0.022 \\
\hline Coronary heart disease & $22(6.3)$ & $10(6.1)$ & 0.934 \\
\hline Cerebrovascular disease & $12(3.4)$ & $8(4.9)$ & 0.429 \\
\hline COPD & $52(14.8)$ & $32(19.4)$ & 0.184 \\
\hline Asthma & $13(3.7)$ & $4(2.4)$ & 0.451 \\
\hline Chronic kidney disease & $18(5.1)$ & $7(4.2)$ & 0.667 \\
\hline Chronic liver disease & $16(4.6)$ & $9(5.5)$ & 0.653 \\
\hline Self-reported habitual snoring & $140(39.8)$ & $88(53.3)$ & 0.004 \\
\hline Modified Mallampati score & & & 0.998 \\
\hline I & $117(33.7)$ & $54(33.5)$ & \\
\hline II & $122(35.2)$ & $57(35.4)$ & \\
\hline III/IV & $108(31.1)$ & $50(31.1)$ & \\
\hline Neck circumference, $\mathrm{cm}$ & $35.1 \pm 3.3$ & $37.3 \pm 3.4$ & $<0.001$ \\
\hline Baseline SBP, mm Hg & $132 \pm 20$ & $136 \pm 20$ & 0.023 \\
\hline Baseline heart rate, beats/min & $75 \pm 14$ & $72 \pm 13$ & 0.022 \\
\hline Baseline $\mathrm{SpO}_{2}, \%$ & $98 \pm 2$ & $98 \pm 2$ & 0.378 \\
\hline \multicolumn{4}{|l|}{ Procedural characteristics } \\
\hline Sedation time, min & $10.3 \pm 4.7$ & $10.6 \pm 5.7$ & 0.630 \\
\hline Procedure time, min & $7.2 \pm 4.4$ & $6.9 \pm 5.1$ & 0.526 \\
\hline Bronchoscopic washing & $259(73.6)$ & $118(71.5)$ & 0.622 \\
\hline Endobronchial biopsy & $56(15.9)$ & $24(14.6)$ & 0.689 \\
\hline Bronchoscopic brushing & $1(0.3)$ & $0(0)$ & $>0.999$ \\
\hline Transbronchial lung biopsy & $2(0.6)$ & $2(1.2)$ & 0.596 \\
\hline
\end{tabular}


Table 1. Continued

\begin{tabular}{|lccc|}
\hline & Nonsnorers $(\mathbf{n}=\mathbf{3 5 2})$ & Snorers $(\mathbf{n}=\mathbf{1 6 5})$ & \\
\hline Pharmacological characteristics & & & \\
Total dose of midazolam, mg & $4.2 \pm 1.4$ & $4.0 \pm 1.2$ & 0.055 \\
Fentanyl & $10(2.8)$ & $12(7.3)$ & 0.020 \\
\hline
\end{tabular}

Values are presented as number (\%) or mean \pm standard deviation.

BMI: body mass index; ASA: American Society of Anesthesiologists; COPD: chronic obstructive pulmonary disease; SBP: systolic blood pressure; $\mathrm{SpO}_{2}$ : pulse oximeter oxygen saturation.
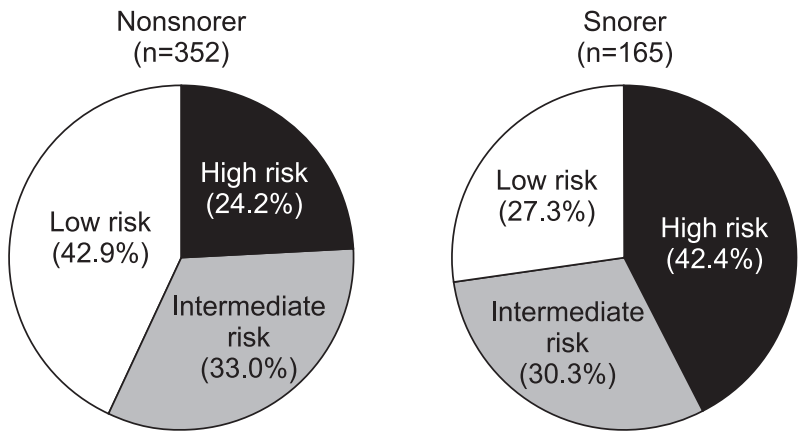

Figure 1. Proportion of snorers and nonsnorers with low, intermediate, and high risk of obstructive STOP-Bang (Snoring, Tiredness, Observed apnea, high blood Pressure-Body mass index, Age, Neck circumference and Gender) questionnaire.

sedation. Table 1 summarizes patient, procedural, and pharmacological characteristics. Snorers were significantly older and predominantly male compared with nonsnorers. Snorers had a higher BMI and neck circumference than nonsnorers. Snorers were more likely to be ever-smokers and have comorbid diabetes mellitus. Although patients who snored during the procedure were more likely to report habitual snoring, approximately half of snorers did not report habitual snoring, whereas nearly $40 \%$ of nonsnorers reported habitual snoring. The modified Mallampati score was similar in both snorers and nonsnorers. The mean dose of midazolam did not differ significantly between the groups, but the use of fentanyl was more frequent in snorers.

The prevalence of a STOP-Bang score $\geq 3$ was $61.9 \%$ (320/517), whereas 200 of the 352 nonsnorers (56.8\%) and 120 of the 165 snorers $(72.7 \%)$ had a STOP-Bang score $\geq 3$ $(\mathrm{p}=0.001)$. When the alternative scoring model of the STOPBang questionnaire was used, $42.4 \%$ of snorers and $24.2 \%$ of nonsnorers were classified as having a high risk of moderate to severe OSA (Figure 1).

In multivariable analysis, snoring during bronchoscopy was significantly associated with a STOP-Bang score $\geq 3$ after adjustment for the presence of diabetes mellitus, chronic obstructive pulmonary disease, chronic kidney disease, and stroke (adjusted odds ratio, 1.91; 95\% confidence interval, $1.26-2.89 ; \mathrm{p}=0.002$ ) (Table 2).
Table 2. Multivariable analysis of factors associated with the risk of obstructive sleep apnea

\begin{tabular}{|lccc|}
\hline & aOR & 95\% CI & p-value \\
\hline Snoring during bronchoscopy & & & \\
No & 1 & & \\
Yes & 1.91 & $1.26-2.89$ & 0.002 \\
Diabetes mellitus & & & \\
No & 1 & & \\
Yes & 2.51 & $1.42-4.44$ & 0.001 \\
COPD & & & \\
No & 1 & & \\
Yes & 1.65 & $0.97-2.79$ & 0.062 \\
Chronic kidney disease & & & \\
No & 1 & & \\
Yes & 2.62 & $0.85-8.14$ & 0.095 \\
\hline Stroke & & & \\
No & 1 & & 0.104 \\
\hline Yes & 2.89 & $0.80-10.4$ & \\
\hline
\end{tabular}

aOR: adjusted odds ratio; CI: confidence interval; COPD: chronic obstructive pulmonary disease.

\section{Discussion}

In the present study, we found that two-thirds of patients undergoing bronchoscopy with moderate sedation were at risk of OSA based on the screening questionnaire. A third of patients snored during the procedure. Snoring during bronchoscopy predicted patients who were at risk of OSA after adjustment for comorbidities.

Snoring is a sleep-related sound caused by vibration of the soft tissue in the upper airway under conditions of inspiratory airflow limitation ${ }^{4}$. Snoring is generated by high-frequency opening and closing of the upper airway structures, including the tongue base and soft palate, aided by the adhesive properties of mucosal secretions ${ }^{4}$. The associations of snoring with hypertension, myocardial infarction, and stroke were reported in the early $1990 \mathrm{~s}^{19-22}$, and habitual snorers were found to be more likely to have moderate to severe OSA in the general 
population ${ }^{1}$. Recently, the amount of time spent snoring was demonstrated to be correlated with the extent of asymptomatic carotid artery stenosis ${ }^{23}$.

Intravenous sedation should be provided to patients undergoing flexible bronchoscopy, particularly when no contraindications to sedation are present ${ }^{24}$. Intravenous midazolam is the preferred sedative for bronchoscopy because of its relatively rapid onset of action and short half-life compared with those of other benzodiazepines. Midazolam induces central nervous system depression, partially by increasing the activity of $\gamma$-aminobutyric acid, the major inhibitory neurotransmitter in the brain ${ }^{25}$, while also increasing upper airway resistance leading to obstructive apnea ${ }^{26}$. Moreover, when patients undergo bronchoscopy in the supine position, they may have a higher risk of upper airway collapse than patients who undergo gastrointestinal endoscopy in the left lateral decubitus position.

Studies evaluating the risk of OSA in patients undergoing bronchoscopy with moderate sedation are scarce, but it has been reported that approximately $40 \%$ of patients undergoing routine and advanced gastrointestinal endoscopy are at risk of OSA ${ }^{15,27,28}$. In our study regarding flexible bronchoscopy, approximately $60 \%$ of patients were at risk of OSA.

Sharara et al. ${ }^{29}$ reported that persistent snoring under moderate sedation during colonoscopy was a strong predictor of OSA, which was confirmed by out-of-center sleep testing. However, in their study, participants who had major comorbidities and underwent the procedure on an inpatient basis were excluded. By contrast, we enrolled both inpatients and outpatients regardless of comorbidities. In this unselected cohort, snoring during bronchoscopy was significantly associated with the risk of OSA after adjustment for the comorbidities frequently associated with OSA.

Patients with OSA may experience adverse events during procedures with sedation ${ }^{15}$. However, adverse events in undiagnosed OSA patients undergoing bronchoscopy with moderate sedation remain poorly recognized. Previous studies on the risk of adverse events have focused on populations undergoing gastrointestinal endoscopy. Patients at high risk of OSA had increased cardiopulmonary events when they underwent advanced endoscopic procedures such as endoscopic retrograde cholangiopancreatography and endoscopic ultrasound ${ }^{15}$ but not when they underwent routine esophagogastroduodenoscopy and colonoscopy $y^{27,28,30-32}$. Differences in the duration and depth of sedation as well as in patient positioning during procedures may account for the different rates of cardiopulmonary events. Although flexible bronchoscopy is a minimally invasive diagnostic procedure, it is generally considered to have a greater risk of cardiopulmonary events than gastrointestinal endoscopy. Consequently, further investigation is warranted to evaluate cardiopulmonary events in patients undergoing bronchoscopy with moderate sedation.

To appreciate the results of our study appropriately, we have to recognize its limitations. First, we were unable to confirm the diagnosis of OSA using polysomnography in patients with a STOP-Bang score $\geq 3$. However, the STOP-Bang questionnaire has been validated and its high sensitivity in detecting moderate to severe OSA has been documented repeatedly ${ }^{18}$. Second, capnography monitoring was not applied; although capnography detects episodes of apnea or hypoventilation, it is not widely used in routine practice.

In conclusion, we found that undiagnosed OSA, estimated using a screening questionnaire, was prevalent in patients undergoing bronchoscopy with moderate sedation. Snoring during bronchoscopy was highly predictive of patients at high risk of OSA. Snoring during the procedure may help uncover undiagnosed OSA and triage patients who need referral for polysomnography.

\section{Authors' Contributions}

Conceptualization: Lee J, Cho J. Methodology: Lee J, Cho J. Formal analysis: Cho J. Investigation: Lee J, Cho J, Choi SM, Park YS, Lee CH, Lee SM. Writing - original draft preparation: Lee J, Cho J. Writing - review and editing: Lee J, Cho J. Approval of final manuscript: all authors.

\section{Conflicts of Interest}

No potential conflict of interest relevant to this article was reported.

\section{Funding}

No funding to declare.

\section{References}

1. Young T, Palta M, Dempsey J, Skatrud J, Weber S, Badr S. The occurrence of sleep-disordered breathing among middleaged adults. N Engl J Med 1993;328:1230-5.

2. Peppard PE, Young T, Barnet JH, Palta M, Hagen EW, Hla KM. Increased prevalence of sleep-disordered breathing in adults. Am J Epidemiol 2013;177:1006-14.

3. Jordan AS, McSharry DG, Malhotra A. Adult obstructive sleep apnoea. Lancet 2014;383:736-47.

4. Kryger MH, Roth T, Dement WC. Principles and practice of sleep medicine. Philadelphia: Elsevier; 2016.

5. Leger D, Bayon V, Laaban JP, Philip P. Impact of sleep apnea on economics. Sleep Med Rev 2012;16:455-62.

6. Marshall NS, Wong KK, Liu PY, Cullen SR, Knuiman MW, Grunstein RR. Sleep apnea as an independent risk factor 
for all-cause mortality: the Busselton Health Study. Sleep 2008;31:1079-85.

7. Young T, Finn L, Peppard PE, Szklo-Coxe M, Austin D, Nieto FJ, et al. Sleep disordered breathing and mortality: eighteen-year follow-up of the Wisconsin sleep cohort. Sleep 2008;31:1071-8.

8. Young T, Evans L, Finn L, Palta M. Estimation of the clinically diagnosed proportion of sleep apnea syndrome in middleaged men and women. Sleep 1997;20:705-6.

9. Finkel KJ, Searleman AC, Tymkew H, Tanaka CY, Saager L, Safer-Zadeh E, et al. Prevalence of undiagnosed obstructive sleep apnea among adult surgical patients in an academic medical center. Sleep Med 2009;10:753-8.

10. Singh M, Liao P, Kobah S, Wijeysundera DN, Shapiro C, Chung F. Proportion of surgical patients with undiagnosed obstructive sleep apnoea. Br J Anaesth 2013;110:629-36.

11. Chung F, Yegneswaran B, Liao P, Chung SA, Vairavanathan S, Islam S, et al. STOP questionnaire: a tool to screen patients for obstructive sleep apnea. Anesthesiology 2008;108:812-21.

12. Netzer NC, Stoohs RA, Netzer CM, Clark K, Strohl KP. Using the Berlin Questionnaire to identify patients at risk for the sleep apnea syndrome. Ann Intern Med 1999;131:485-91.

13. Ramachandran SK, Josephs LA. A meta-analysis of clinical screening tests for obstructive sleep apnea. Anesthesiology 2009;110:928-39.

14. Ramachandran SK, Kheterpal S, Consens F, Shanks A, Doherty TM, Morris M, et al. Derivation and validation of a simple perioperative sleep apnea prediction score. Anesth Analg 2010;110:1007-15.

15. Cote GA, Hovis CE, Hovis RM, Waldbaum L, Early DS, Edmundowicz SA, et al. A screening instrument for sleep apnea predicts airway maneuvers in patients undergoing advanced endoscopic procedures. Clin Gastroenterol Hepatol 2010;8:660-5.e1.

16. Chhajed PN, Aboyoun C, Malouf MA, Hopkins PM, Plit M, Grunstein RR, et al. Management of acute hypoxemia during flexible bronchoscopy with insertion of a nasopharyngeal tube in lung transplant recipients. Chest 2002;121:1350-4.

17. Chung F, Yang Y, Brown R, Liao P. Alternative scoring models of STOP-Bang questionnaire improve specificity to detect undiagnosed obstructive sleep apnea. J Clin Sleep Med 2014;10:951-8.

18. Chung F, Abdullah HR, Liao P. STOP-Bang Questionnaire: a practical approach to screen for obstructive sleep apnea. Chest 2016;149:631-8.

19. Koskenvuo M, Kaprio J, Heikkila K, Sarna S, Telakivi T, Partinen M. Snoring as a risk factor for ischaemic heart disease and stroke in men. Br Med J (Clin Res Ed) 1987;294:643.

20. Schmidt-Nowara WW, Coultas DB, Wiggins C, Skipper BE, Samet JM. Snoring in a Hispanic-American population. Risk factors and association with hypertension and other morbidity. Arch Intern Med 1990;150:597-601.

21. D’Alessandro R, Magelli C, Gamberini G, Bacchelli S, Cristina E, Magnani B, et al. Snoring every night as a risk factor for myocardial infarction: a case-control study. BMJ 1990;300:1557-8.

22. Seppala T, Partinen M, Penttila A, Aspholm R, Tiainen E, Kaukianen A. Sudden death and sleeping history among Finnish men. J Intern Med 1991;229:23-8.

23. Lee SA, Amis TC, Byth K, Larcos G, Kairaitis K, Robinson TD, et al. Heavy snoring as a cause of carotid artery atherosclerosis. Sleep 2008;31:1207-13.

24. Du Rand IA, Blaikley J, Booton R, Chaudhuri N, Gupta V, Khalid S, et al. British Thoracic Society guideline for diagnostic flexible bronchoscopy in adults: accredited by NICE. Thorax 2013;68 Suppl 1:i1-44.

25. Reves JG, Fragen RJ, Vinik HR, Greenblatt DJ. Midazolam: pharmacology and uses. Anesthesiology 1985;62:310-24.

26. Montravers P, Dureuil B, Desmonts JM. Effects of i.v. midazolam on upper airway resistance. Br J Anaesth 1992;68:27-31.

27. Mehta PP, Kochhar G, Kalra S, Maurer W, Tetzlaff J, Singh G, et al. Can a validated sleep apnea scoring system predict cardiopulmonary events using propofol sedation for routine EGD or colonoscopy? A prospective cohort study. Gastrointest Endosc 2014;79:436-44.

28. Boese ML, Ransom RK, Roadfuss RJ, Todd A, McGuire JM. Utility of the Berlin Questionnaire to screen for obstructive sleep apnea among patients receiving intravenous sedation for colonoscopy. AANA J 2014;82:38-45.

29. Sharara AI, El Zahabi L, Maasri K, Hashash JG, Mansour N, Skoury A, et al. Persistent snoring under conscious sedation during colonoscopy is a predictor of obstructive sleep apnea. Gastrointest Endosc 2010;71:1224-30.

30. Khiani VS, Salah W, Maimone S, Cummings L, Chak A. Sedation during endoscopy for patients at risk of obstructive sleep apnea. Gastrointest Endosc 2009;70:1116-20.

31. Cha JM, Jeun JW, Pack KM, Lee JI, Joo KR, Shin HP, et al. Risk of sedation for diagnostic esophagogastroduodenoscopy in obstructive sleep apnea patients. World J Gastroenterol 2013;19:4745-51

32. Andrade CM, Patel B, Gill J, Amodeo D, Kulkarni P, Goldsmith S, et al. Safety of gastrointestinal endoscopy with conscious sedation in patients with and without obstructive sleep apnea. J Clin Gastroenterol 2016;50:198-201. 